\title{
Delay of gratification in young adults with Down syndrome
}

\author{
Monica Cuskelly, Maria Einam, and Anne Jobling \\ Fred and Eleanor Schonell Special Education Research Centre, Graduate school of education, University of \\ Queensland
}

\begin{abstract}
Thirty-one young adults (17-23 years of age) with Down syndrome participated in two self-imposed delay of gratification trials. Thirty-six and forty-eight percent waited for the experimenter to return ( 15 minutes) on Trials I and 2 respectively, and thirty-six percent waited for the experimenter on both occasions. Expressive language differentiated those who waited from those who did not. A discriminant analysis which included measures of expressive language, temperament characteristics and parental attitudes to childrearing gave very good separation of the two groups. Directions for future researched are discussed.
\end{abstract}

Keywords - Self-regulation; delay of gratification, Down syndrome

\section{Introduction}

In 1990, Whitman proposed that intellectual disability could be usefully thought of as a self-regulatory disorder. A series of commentaries followed his paper with most authors suggesting his position had some merit, although it was somewhat extreme (see, for example, Baer, 1990; Kendall, 1990). Since that publication there have been very few papers published in the area of intellectual disability that have explicitly used a self-regulatory framework.

Self-regulation is a developmental phenomenon with predictable changes as individuals age (see Kopp, 1982). In its earliest manifestation it can be observed in infants' ability to manage their responses to external stimuli (Ganiban, Wagner \& Cicchetti, 1990) and in its mature form it is a very complex behaviour incorporating goal setting, selecting the appropriate strategies for meeting that goal, avoiding distracting temptations (Bandura, 1991), and managing one's emotions as one works toward the goal (Whitman, O'Callaghan \& Sommer, 1997).

Self-imposed delay of gratification refers to an individual's ability to forfeit an immediate goal in order to obtain a preferred goal which is more distant in time. It differs from self-control as described by Kopp (1991) as the individual decides to wait for the preferred goal, rather than being instructed to wait by another. It has been identified as one of the most important skills in self-regulation (Logue, King, Chavarro, \& Volpe, 1990). Clear individual differences in ability to self-impose delay of gratification exist by the time typically developing children are four years of age (Cournoyer \& Trudel, 1991) and have been found to be predictive of both cognitive and social competence at adolescence (Mischel, Shoda, \& Rodriguez, 1989; Shoda, Mischel \& Peake, 1990).

\section{Role of language in self-regulation}

Both Luria (1961) and Vygotsky (1962) hypothesized that private speech was a necessary precursor to the ability to manage one's own behaviour in the absence of external controls. Rodriguez, Mischel and Shoda (1989) found an association between receptive language and waiting time in a self-imposed delay task in children with no developmental delay but who had social adjustment and impulse control problems. Vaughn, Kopp and Krakow (1984) found a similar association for externally imposed waiting in young typically developing children. Both sets of authors suggested that the relationship probably reflects underlying cognitive ability, although Vaughn et al. do acknowledge that their results may be taken as support for Luria's view about the role of speech and language in self-regulation. It could be expected that expressive language would have an even greater association (Glenn \& Cunningham, in press), however this does not appear to have been investigated.

\section{Self-regulation in individuals with Down syndrome}

In one of the few studies of self-regulation of children with Down syndrome, Kopp (1990) found that at a developmental age of 24 to 40 months (chronological age 31-60 months) they were less able to inhibit their behaviour than 
were a group of typically developing comparison children of the same developmental age. In the tasks used by Kopp, children were instructed to wait until given permission by the examiner to touch a tempting stimulus. Sixty-six percent of the children with Down syndrome waited less than 10 seconds (the average delay time for normally developing 18 month olds) whereas only eighteen percent waited such a short time in the comparison group.

In a recent study, Zhang and Cuskelly (2000) found that the majority of their sample of children with Down syndrome (mental age $=4$ years) were significantly less able to delay gratification in a self imposed task than were typically developing children (chronological age $=4$ years). A number of possibilities may account for the difficulties children with Down syndrome experience in self-regulatory tasks requiring inhibition. Of particular interest is the role of language in enabling children to manage their own behaviour. Children with Down syndrome have linguistic difficulties that are separate from and greater than their cognitive delay (Gunn \& Crombie 1996), and this may explain, in part, the difficulty they demonstrate in the inhibiting their behaviour.

\section{The role of temperament in self-regulation}

A number of writers have implicated temperament as a contributor to the ability to self-regulate (see, for example, Kochanska, Murray, Jacques, Koenig, \& Vandegeest, 1996; Rothbart \& Jones, 1998). In one of the few empirical investigations of this association, Silverman and Ragusa (1990) found that Impulsivity, as measured on an inventory developed by Buss, Plomin and Willerman (1973), was negatively related to other-imposed delay performance $(r=$ -.39 and $r=-.31$ ). In addition, a moderate negative relationship between delay and Sociability was found $(r=-.42)$ as well as a positive correlation between delay performance and Attention Span/Persistence $(r=.37)$. This latter scale came from the Colorado Childhood Temperament Inventory (Rowe \& Plomin, 1977).

Studies of the temperament of children with Down syndrome have indicated that there are no clear temperamental profiles which distinguish those with Down syndrome from typically developing peers (Ganiban et al., 1990). There are, however, indications that persistence is an area of difficulty for these individuals (Gunn \& Berry, 1985; Gunn \& Cuskelly, 1991) which suggests that delaying gratification for an extended period may prove difficult for this group.

\section{Role of parents in the development of the capacity to self-regulate}

Parents have a central role in theories of the development of self-regulation (see for example, Bandura, 1986; Kopp, 1990; Vygotsky, 1962). This role involves modelling the various behaviours that constitute self-regulation, assisting children to control their behaviour, for example, by providing verbal structures they cannot supply for themselves, and gradually ceding control of their behaviours as they become competent. Silverman and Ragusa (1990) investigated this relationship using the Parental Attitudes towards Childrearing Questionnaire (Easterbrooks \& Goldberg, 1984) and found the scale Encouragement of Independence $(r=.43)$ and Strictness $(r=-.28, \mathrm{p}=.06)$ to be related to delay.

Parental behaviour may also influence the development of self-regulation indirectly. Harris, Kasari and Sigman (1996) in their investigation of joint attention between parents and children with Down syndrome, suggested that children whose parents encourage independent activity are likely to have larger vocabularies than those who parents who do not give autonomy such priority.

\section{Consistency across tasks}

Clearly if the ability to delay gratification is predictive of later development as claimed by Mischel and his colleagues (Mischel, et al., 1989; Shoda, et al., 1990) then it would be expected to be a relatively stable behaviour. As far as could be ascertained no examination of the stability of selfimposed delay of gratification has been undertaken. There is evidence, however, that inhibitory control in complying with an adult's direction is relatively stable although correlations are usually in the moderate range. Vaughn, et al. (1984) found low to moderate correlations across 4 examiner imposed tasks at age 30 months $(r=.20-.46)$. Reed, Pien and Rothbart (1984) also found a moderate correlation $(r=.5 \mathrm{l})$ across two inhibitory control tasks with older children (40-49 months). Silverman and Ragusa (1990) used four tasks to examine impulse control in young children (24 \pm 1 month). They calculated measures of internal consistency using the four scores with coefficient alphas ranging from .61 - .70. In Kopp's (1990) examination of consistency of inhibitory control in young children with Down syndrome she found a zero correlation across tasks for the children with Down syndrome but $r=.71$ for the comparison children.

\section{Aims of the study}

The present study was intended to establish if adults with Down syndrome demonstrate the ability to wait in a situation where they have imposed the task upon themselves. The concurrent role of expressive and receptive language was investigated as was that of temperament, and parental childrearing attitudes. Observable strategies used during the waiting period were examined and the participants' understanding of strategies which assisted waiting were also investigated.

\section{Method}

\section{Participants}

Thirty-one young adults with Down syndrome who were aged 17 to 23 years $(M=19.8$ years, $S D=1.3$ years $)$ took part in the study. All were Trisomy 21. Of this group, 13 were females $(M=19.7$ years, $S D=1.6$ years $)$ and 18 were males $(M=19.9$ years, $S D=1.1$ years $)$. All of the partici- 
pants were living at home with their families and were no longer attending school. The parents of 29 of the young people completed questionnaires.

\section{Selection and recruitment}

Young adults with Down syndrome and their families who were in the age range established for the study ( 17 to 24 years) were identified and recruited from the ongoing longitudinal study of individuals with Down syndrome at the Schonell Centre, the University of Queensland, Brisbane, Australia. Forty-nine suitable participants were identified from the database of the Down Syndrome Program. Eighteen families declined the invitation to participate citing such reasons as ill health of the young person, lack of time or unavailability of transport.

\section{Measures}

Self-imposed delay of gratification tasks. This task has been used by Mischel (1974) to investigate self-imposed delay of gratification. Two versions were used on two separate occasions. One used edible rewards following Mischel's procedure and the second allowed the adult to choose between two magazines. This choice of rewards was established through discussion with staff involved in a literacy program for young adults with Down syndrome.

Knowledge of delay rules. These questions are based on procedures used by Mischel and Mischel (1983) and subsequently by Rodriguez, et al. (1989). Young adults were asked to respond to three questions that assessed preference for rewards covered versus rewards exposed during waiting period; preference for an abstract versus consummatory strategy; and preference for a task oriented persus consummatory strategy. Prior to being directly asked about their knowledge they were asked more open-ended questions about what they had done to help themselves to wait.

The Self-Control Rating Scale (SCRS) (Kendall \& Wilcox, 1979), which comprises 33 items rated on a 7-point Likert scale, was completed by parents. For each score, a rating of 1 indicates maximum self-control and a rating of 7 denotes maximum impulsivity. The authors report good test-retest reliability (.84 over $3-4$ weeks) and internal consistency (Cronbach's alpha $=.98)$. There is no evidence of significant gender differences with the SCRS. The SCRS measures one major factor, cognitive-behavioural self-control, with the cognitive component of this factor being made up of a child's ability to deliberate, problem-solve, plan and evaluate and the behavioural component being based on the child's ability to execute or inhibit behaviours.

The Parental Attitudes towards Childrearing (Easterbrooks \& Goldberg, 1984) is made up of 51 items rated on 6-point Likert scale. The items were initially selected to address issues salient to parents of toddlers but are applicable to a wider age range and are presented in terms that are not age restrictive. The scale contains 10 items that provide a measure of parental warmth, 9 items that are indicative of parental encouragement of independence, 13 items that denote parental strictness and 19 items that are descriptive of the level of aggravation felt by parents. The scale has yielded sufficiently high internal consistency (Cronbach's alpha = $.69)$.

The EASI - III Temperament Scale (Buss \& Plomin, 1975) consists of 50 items that can be completed by the individual or by a parent (with some minor rewording) to give a measure of the parent's rating of their offspring's temperament. The items are rated on a 5-point Likert scale and are divided into 10 subscales which are combined to create four scales reflecting aspects of temperament: Emotionality (15 items), Activity (10 items), Sociability (5 items) and Impulsivity (20 items). Parents were asked to complete the scale with regard to their adult child in this study.

The Peabody Picture Vocabulary Test-III (PPVT-III) (Dunn \& Dunn, 1997) assesses receptive vocabulary. It is suitable for use with individuals between 2.5 and 90 years. The authors have reported strong internal consistency, and testretest reliability and adequate validity. It has been found to be suitable to use with individuals with Down syndrome (Pulman, 1999).

The Expressive Vocabulary Test (EVT) (Williams, 1997) assesses expressive vocabulary and word retrieval. It is suitable for use with individuals between 2.5 and 90 years. Williams reports high internal consistency, and test-retest reliability and adequate validity. It also has been used successfully with individuals with Down syndrome (Pulman, 1999).

\section{Procedure}

Young adults with Down syndrome who were suitable for the study were identified from the database associated with the Down Syndrome Program at the Schonell Centre. Seventeen of the possible participants identified were attending a literacy program at the Centre. After gaining their consent to participate in the study, the seventeen young people completed the waiting trials at the laboratory on two separate occasions during their attendance at the literacy program. Parent questionnaires were sent to the families by mail and a stamped addressed envelope was used to expedite their return.

The remaining families were contacted by telephone and appointments were made to attend the Schonell Centre on two separate occasions, for those who were interested in taking part in the study. During the young person's first visit, their parent completed the questionnaires. All laboratory procedures were videotaped.

Experimental procedures. Two female research assistants carried out the procedures. The same individual saw the young adult on both occasions. Young people completed two separate trials on different occasions. To ensure the young adults understood the contingency used in the task, a teaching procedure was conducted prior to the administration of the first task and the participant was required to indicate understanding of the contingencies. The teaching procedures comprised teaching the function of the bell to get the experimenter to return and teaching the contin- 
gency of 'wait and get', that is, if the young person waited then she/he received the magazine or edible item. Both procedures were taught to a maximum of 5 times and 2 consecutive correct responses showing understanding of the procedures were required in order for the trial to proceed. Prior to the second administration, understanding was checked. If there was any question about the participant's understanding, the teaching and querying procedure was again implemented, with the same criteria as above. No participant was unable to proceed during the first trial, however one young woman was unable to correctly answer the questions probing understanding on the second trial.

Once the procedures were taught, the young person's preference for reward was ascertained using the procedures established by Mischel (1974). The young adults were required to indicate their preference for one of two reward alternatives. They were then told they could obtain their preferred reward by waiting, but that if they chose to stop waiting they would receive the less preferred reward. Understanding was checked after the initial explanation. Five teaching episodes were allowed if needed by the participant.

Once the young adults understood the task, they were informed that the experimenter needed to undertake a task elsewhere and when she returned the individual could have the chosen reward. The time the experimenter would be away was not revealed to the participants. The waiting period was 15 minutes, or until the person pressed the bell, or actually began to consume his/her preferred choice, whichever came first.

If participants were able to wait until the experimenter returned they were then able to have their preference, i.e. two marshmallows. However, if they rang the bell or consumed a marshmallow, they were only able to have one marshmallow. If the young person had not been administered the PPVT-III previously, this was completed after the waiting trial.

On the second occasion, the participants were asked to indicate their preference for one of two rewards, a magazine about psychological research or a magazine orientated toward teenagers with articles about popular music and television programs. The same waiting procedure that was used in the first trial was then carried out.

After the second trial, participants were asked a number of questions to determine what types of strategies they used to wait for the desired goal. The participants were also asked three questions to determine their understanding of successful delay strategies as devised by Mischel and Mischel, (1983). These questions assessed preference for the rewards to be covered or exposed; preference for abstract versus consummatory strategies; and preference for a task oriented versus consummatory strategy. If the young person had not completed the EVT previously, this was administered after the waiting trial.

Both sessions were videotaped for the purpose of establishing the strategies actually used by the participants during the waiting period. Behaviours to be categorized had been developed by Zhang (unpublished document, available from the first author) and included the following: task monologue (talking to self about the task but not selfassurance), nontask monologue (talking about unrelated matters), self-assurance (talking related to adult's capacity to perform the task), bell avoidance (pushes bell away), physical distraction but remains in chair, leaves the chair, sitting still (stays in chair and does not engage in physical distraction), target oriented activity (any activity that focuses on the reward but does not violate the rule), negative behaviour (e.g. temper tantrum). The waiting time was divided into 15 second segments and the dominant behaviour was recorded.

\section{Results}

\section{Preliminary analyses}

As many of the variables used in these analyses were not normally distributed, nonparametric tests were used except where otherwise indicated. Age was not correlated with either EVT or PPVT-III scores, nor with waiting times, so it was omitted from all further analyses. Wilcoxon Rank tests were conducted to establish if scores on any of the measures listed above differed according to sex, but all tests were nonsignificant, so data were combined for the analyses reported below.

\section{Waiting time}

Waiting times across the two occasions were significantly positively correlated $(r h o=.80, p<.001)$ and there was no difference between the times waited on the two trials using Wilcoxon Matched Pairs Signed Ranks Test (Trial $1 M=$ 427.3 secs $S D=398.4$; Trial $2 M=477.9, S D=425.5$ ). Clearly there were very large standard deviations both for Trial 1 and Trial 2. Two distinct groups were apparent those who waited the entire 15 minutes until the experimenter returned, and those who waited a very little time. There were also a few individuals who waited for some time but ended the session before the experimenter returned. Three groups were created for each waiting trial: those who waited for the experimenter to return i.e. 15 minutes, (waiters; Trial $1 n=11$; Trial $2 n=14$ ); those who waited less than 3 minutes, (nonwaiters; Trial $1 n=14$; Trial $2 n=14$ ) and those whose waiting time was somewhere in between, (intermediate; Trial $1 n=6$; Trial $2 n=2$ ). Mean waiting times for the two groups who did not wait the full $15 \mathrm{~min}-$ utes are displayed in Table 1. All individuals who waited on Trial 1 also waited on Trial 2.

\section{Relationship of Language scores to waiting time}

Scores on the PPVT-III and the EVT were positively correlated $(r h o=.52, \mathrm{p}<.01)$, but their associations with waiting times differed. Scores of the EVT were positively correlated with waiting time at both trials 2 (Trail 1 rho $=.53, p<.01$; Trial $2 r h o=.47, p<.01)$. PPVT-III scores were not associated with waiting time at either trial. Mann Whitney tests 


\begin{tabular}{lllll}
\hline & Trial I & \multicolumn{3}{c}{ Trial 2 } \\
\hline & $\begin{array}{l}\text { intermediate } \\
(\mathrm{n}=6)\end{array}$ & $\begin{array}{l}\text { nonwaiters } \\
(\mathrm{n}=14)\end{array}$ & $\begin{array}{l}\text { intermediate } \\
(\mathrm{n}=2)\end{array}$ & $\begin{array}{l}\text { nonwaiters } \\
(\mathrm{n}=14)\end{array}$ \\
$\begin{array}{l}\text { Mean waiting } \\
\text { time }\end{array}$ & 480.17 & 33.21 & 385.00 & 38.93 \\
$\begin{array}{l}\text { Standard } \\
\text { deviation }\end{array}$ & 133.24 & 42.80 & 134.35 & 45.58 \\
$\begin{array}{l}\text { Minimum } \\
\text { waiting time }\end{array}$ & 340 & 5 & 290 & 0 \\
$\begin{array}{l}\text { Maximum } \\
\text { waiting time }\end{array}$ & 655 & 166 & 480 & 165 \\
\hline
\end{tabular}

Table I. Waiting times (in seconds) for the two groups of young adults who did not wait on two occasions

showed significant differences between those who waited and the nonwaiters on the EVT on both trials (Trial 1 $U=17, p<.001$; Trial $2 U=43, p<.01$ ) with waiters having higher EVT scores on both occasions (Trial I Waiters Mean Rank $=18.45$, EVT M age equivalent $=76.36$, $S D=3.07$, Nonwaiters Mean Rank $=8.71$, EVT M age equivalent $=59.43, S D=3.67$; Trial 2 Waiters Mean Rank $=$ 19.13, EVT M age equivalent $=71.67, S D=3.35$, Nonwaiters Mean Rank $=10.57$, EVT $M$ age equivalent $=57.71$, $S D=3.54)$. PPVT-III scores did not differ significantly between the two groups on either trial.

Within those who did not wait for the experimenter to return two groups could be distinguished - those who rang the bell to terminate the session and those who violated by eating the marshmallows or reading the magazine. EVT scores were significantly different across these two groups at Trial 1 (Mann Whitney $U=13.0, p<.05$ ) but not at Trial 2. EVT scores were higher for those who rang the bell at Trial 1 (Mean Rank $=11.82$, EVT $\mathrm{M}$ age equivalent $=$ $67.5, S D=12.1$ ) than for those who violated (Mean Rank $=5.86, \mathrm{M}$ age equivalent $=51.7, S D=15.8)$. PPVT-III scores were not different across these two groups on either occasion. Numbers were very small in these analyses and so results need to be treated cautiously.

\section{Strategy use and relationship to waiting time}

Strategy use was examined using proportions as we wished to identify those strategies that were most likely to result in successful waiting. Chi square analysis showed that some strategies were used more often than others, both during Trial 1 (Chi square $=27.13, p<.001)$ and Trial $2($ Chi square $=26.13, p<.001)$. During Trial 1 , only two strategies were used by more than half the group, physical distraction and sitting still. Task monologue, nontask monologue, self-assurance, bell avoidance, physical leave, and negative behaviour were all used by less than five percent of the group. The group showed a slightly broader use of strategy during Trial 2 with physical distraction, sitting still, and target orientated activity all being used by more than 50 percent of the participants. Strategies that were used by less than five percent included task monologue, self-assurance, bell avoidance, physical leave, and negative behaviour. The strategy of target oriented activity was the only strat- egy to change its pattern of use over time $(Z=$ $-2.45, \mathrm{p}<.01)$ with increased use during Trial 2 (Trial $1 M=18.64$; Trial $2 M=35.73$ ). None of the three language based strategies were associated with either EVT or PPVT-III scores.

The strategies used by the group who waited were compared with those chosen by those who did not wait. During Trial 1 the use of target oriented activity approached significance between the two groups ( $\mathrm{t}$ test for unequal variance $=-2.03, d f=13.54, p=.06)$ with those who waited using this strategy proportionately less (Waiters $M=2.82, S D=6.02$; Nonwaiters $M=$ $28.57, S D=46.88)$. During Trial 2 the use of nontask monologue was the only one to reach significance ( $\mathrm{t}$ test for unequal variance $=2.28$, $d f=14.11, p<.05)$ and in this case those who waited used talking about unrelated matters proportionately more than those who did not wait (Waiters $M=9.67, S D=15.97$; Nonwaiters $M=0.25, S D=0.92)$.

When questioned about their understanding of the delay rules, $23 \%$ of the group understood the usefulness of selfinstruction to wait, $68 \%$ understood that thinking about abstract qualities were more helpful than thinking about the consummatory qualities of the reward was helpful, and $19 \%$ understood that it would be more helpful to have the reward covered than for it to be exposed. Three percent of the group demonstrated understanding of all three rules. Self-report of the use of the rules revealed a slightly different pattern. Twenty-three percent reported they talked to themselves about waiting, $58 \%$ tried to think about something else and $29 \%$ said they had tried not to look at the reward. Only $6.5 \%$ reported using all three strategies. Knowledge and self-reported use of the delay rules were positively correlated $(r h o=.58, p<.001)$ and both were associated with scores on the PPVT-III (knowledge $r$ ho $=$ $.43, p<.05$; self-reported use $r h o=.42, p<.05)$ but not with the EVT. Greater knowledge was positively correlated with waiting time on Trial $2(r h o=.43, p<.05)$ but not on Trial 1. Self-reported use of strategy was related to waiting time on both trials with use of more strategies being associated with longer waiting (Trial $1 r h o=.38, p<.05$; Trial 2 rho $=.47, p<.01)$.

The impact of knowledge and self-reported use of the delay rules on observed strategy use was tested using a Mann Whitney test. Two groups were formed - those who knew/ reported using a rule and those who did not - and use of related strategies were compared. One difference was significant and one approached significance. Those who reported using self-talk were more likely to have been observed engaging in self-assurance than those who did not $(U=$ $60.0, \mathrm{p}<.01$; Mean rank $=19.43$ and 15.0 respectively) and there was a tendency for those who understood the rule about distracting oneself to engage in more physical distraction $(U=36.0, \mathrm{p}=.06 ;$ Mean rank $=21.5$ and 14 respectively). 


\section{Temperament measures and waiting time}

The measures reported in this section were collected from parents and so contain data for 29 individuals only. Internal consistency was calculated for each of the temperament factors. Alpha coefficients were reasonable for three of the factors (Emotionality $=.82$; Activity $=.75$; Sociability $=.80$ ) but was somewhat lower for the Impulsivity factor $(.57)$, suggesting that caution be used in any interpretations of relationships of this latter scale. None of the scales were correlated. There were no significant associations between measures of temperament and waiting time and waiters did not differ from nonwaiters on any of the scales. The correlations between the subscales of the EASI and waiting time were also calculated and, again, no significant relationships were found.

As the Self-Control Scale has not been used with this population before, the internal consistency of the measure was first established. A high alpha coefficient was found (.87) indicating very good internal reliability. There were no significant relationships between waiting time and the SelfControl Scale on either trial, and waiters and nonwaiters did not differ from each other. There was a negative correlation between scores on the Self-Control Scale and Impulsivity $(r h o=-.58, p<.001)$.

\section{Parental measures and waiting}

Internal consistencies of the subscales of this instrument were low to moderate - Warmth (.53), Encouragement of Independence (.40), Strictness (.59) and Aggravation (.68). Parental reports of strictness and of aggravation were correlated $(r h o=.43, p<.05)$, and both were positively correlated with parental responses on the Self-Control Scale $(r h o=.43$ and .41 , respectively, both $\mathrm{p}<.05)$. There was a trend towards a negative association between strictness and warmth $(r h o=-.36, p=.06)$. There were no significant relationships between parental measures and waiting times and no relationship to either of the language measures.

\section{Discriminant analysis}

In order to ascertain the combined influence of the measures used in this study a discriminant analysis was conducted. For this analysis two groups were formed - those who had waited until the experimenter returned on both trials $(n=11)$ and those who had not $(n=18)$. In the initial phase, all questionnaire measures plus the language scores were put into the analysis. Subscales rather than scales of the EASI were used as they gave better between groups variability. The result of this first analysis was nonsignificant. The only measure to show a significant difference between the groups was expressive language $(F=9.35, p<.01)$. Discriminant analysis which included only the EVT gave a Wilk's Lambda of .74 (Chi-square $=10.03, p<.004)$. An analysis which included the 4 variables with the next best F values (Parental Encouragement, Sociability [subscale of the EASI], Parental Experience of Aggravation, and Decision Time [subscale of the EASI]) with the EVT gave a Wilks' Lambda of .40 (Chi-square $=22.00, p<.001)$ and correctly classified $93 \%$ of the cases. Specifically, it correctly classified $91 \%$ of the group that waited on both trials and $95 \%$ of the group that did not. Adding additional variables did not increase the discrimination appreciably. Parental attitudes and personal characteristics contributed to waiting time, however, the interpretation is somewhat unclear as there were no significant differences on the individual variables, with the exception of the EVT.

\section{Discussion}

This exploratory study of the ability to self-impose delay of gratification in young adults with Down syndrome has revealed that a substantial proportion have gained this skill by adulthood, however an even larger group still find it very difficult to delay beyond a few minutes. The reasons for this difficulty remain unclear, although some indications are available. The research presented here suggests that the differences between young adults with Down syndrome and their typically developing peers, with regard to self-imposed delay of gratification, are not just due to a general developmental lag. Expressive language differentiated those who waited from those who did not as predicted by theories about the importance of self-speech in self-regulation (Luria, 1961; Vygotsky, 1962). It is possible that the difference on the EVT is merely reflecting a difference in intellectual ability, however this argument is somewhat weakened by the fact that receptive language, usually highly correlated with intellectual ability, did not differ between groups. Nevertheless, this possibility needs to be empirically examined and measures of nonverbal ability may be most useful because of the asynchrony between verbal skills and intellectual ability in those with Down syndrome.

All participants who waited for the experimenter to return on Trial 1 also waited on Trial 2. Unfortunately it is not possible to separate out the possible learning effect from the effect of the salience of the two rewards. (It is probable that the magazine was a more powerful reward than were two marshmallows, a view that is supported by the increase in target oriented behaviour during Trial 2.) There is clearly a recurring cost/benefit analysis going on for those who choose to wait - and for those who choose to stop waiting. It is possible, however, for some who did not wait, particularly for those who violated the rules of the experiment, that memory difficulties impeded their performance. They may have forgotten the contingencies which they had previously understood, rather than have made a conscious decision to stop waiting. The role of memory in delay of gratification and other self-regulatory tasks needs to be investigated.

Parental approaches to childraising and temperament measures did not distinguish the groups, however, in combination with the measures of language some parental and individual characteristics were found to provide very good separation between those who waited for the experimenter to return on both occasions and those who did not. As the participants in this study were young adults, parental interactions may have been modified to accommodate increased 
pressures for autonomy, and so have had less impact than on the younger children as demonstrated in the study by Silverman and Ragusa (1990). Longitudinal studies that allow investigation of the roles of parental interactions and individual temperament, and their interaction, in the development of self-regulation are required. The tantalizing work of Harris et al., (1996) regarding parental support for autonomy and vocabulary development may provide some information about indirect ways that parental behaviours impact on development and such leads need to be followed up.

Self-imposed delay of gratification is important not only as a stand-alone ability, but also because it represents the larger arena of self-regulation. Self-regulation is a critical skill if adults with Down syndrome are to be able to take best advantage of the inclusive opportunities being made available to them (Cuskelly, Zhang \& Gilmore, 1998). As it is an important set of skills the developmental sequence and those variables that influence its development need to be identified. Research which focuses on these issues will contribute to our understanding of the processes for children who are developing typically as well, as this work has already suggested that changes in mental age may be insufficient to explain the development of this skill. Associations found in this and other studies between language skill and waiting may not just represent underlying differences in IQ but may indicate a specific role for language in self-regulation.

Observational measures of strategy are somewhat limited, particularly in regard to the use of self-talk as much of this may be sub voce. Glenn and Cunningham (in press) found that $86 \%$ of the adolescents and young adults in their study used private speech, however the social demands of the experimental situation may act to suppress this behaviour, even if it is commonly used in more familiar settings. Some of the participants in this study may have learned to internalize their self-talk and may have been engaging in this behaviour while being recorded as "sitting still". Thus the information on strategy use provided by this study must be treated very cautiously, although it has made apparent that some of the young people actively engaged in behaviours clearly designed to assist them to wait. For example, one young man picked up the reward and placed it under the table, out of sight, others exercised vigorously, and others deliberately pushed the reward away from themselves.

Participants' knowledge of behaviours that would assist waiting was low. Few understood that not seeing the reward would make waiting easier, and a similarly small proportion understood that talking to oneself about waiting would be more effective than talking to oneself about the reward. Sixty-eight percent said that thinking about an abstract quality would be more helpful than thinking about the consummatory properties. Self-reported use of these strategies showed a similar pattern and both knowledge and selfreported use were related to waiting time as was also found by Rodriguez et al. (1989). It may be possible to explicitly teach these rules to young people with Down syndrome rather than wait for them to extract them from their own experiences. Jay, Grote and Baer (1999) have recently demonstrated that individuals with an intellectual disability can be taught to successfully use self-instruction to guide their behaviour.

If we are to fully understand individual differences in the capacity of those with Down syndrome to use self-regulatory skills, a necessary goal if successful interventions are to be designed, there are additional aspects of personal development that need to be included in our research. A number of these have been the focus of substantial amounts of interest (e.g. attentional processes) while others, such as motivation and understanding of self, are only now beginning to be thoroughly investigated by those working with individuals with Down syndrome.

\section{Correspondence}

Dr Monica Cuskelly • Fred and Eleanor Schonell Special Education Research Centre, University of Queensland, Q 4072, Australia •E-mail: m.cuskelly@mailbox.uq.edu.au

\section{References}

Baer, D.M. (1990). Why choose self-regulation as the focal analysis of retardation? American Journal on Mental Retardation, 94, 363-364.

Bandura, A. (1986). Social Foundations of Thought and Action: A Social Cognitive Theory. Englewood Cliffs, NJ: Prentice-Hall.

Bandura, A. (1991). Social cognitive theory of self-regulation. Organizational Behavior and Human Decision Processes, 50, 248-287.

Buss, A.H., \& Plomin, R. (1975). A Temperament Theory of Personality Development. New York: Wiley-Interscience.

Buss, A.H., Plomin, R. \& Willerman, L. (1973). The inheritance of temperaments. Journal of Personality, 41, 513-524.

Cournoyer, M., \& Trudel, M. (1991). Behavioral correlates of self-control at 33 months. Infant Behavior and Development, 14, 497-503.

Cuskelly, M., Zhang, A., \& Gilmore, L. (1998). The importance of self-regulation in young children with Down syndrome. International Journal of Disability, Development and Education, 45, 331-341.

Dunn, L.M \& Dunn, L M. (1997). Peabody Picture Vocabulary Test - Third Edition. Circle Pines, MN: American Guidance Service.

Easterbrooks, M. A., \& Goldberg, W. A. (1984). Toddler development in the family: Impact of father involvement and parenting characteristics. Child Development, 55 , 740-752.

Ganiban, J., Wagner, S., \& Cicchetti, D. (1990). Temperament and Down syndrome. In D. Cicchetti \& M. Beeghly (eds), Children with Down syndrome: A developmental perspective (pp. 63-100). Cambridge: Cambridge University Press.

Glenn, S., \& Cunningham, C. (in press). Self-regulation in children and young people with Down syndrome. In M. Cuskelly, A. Jobling, \& S. Buckley (eds) Down Syndrome Across the Lifespan. London: Whurr. 
Gunn, P. \& Berry, P. (1985). Down's syndrome temperament and maternal response to descriptions of child behavior. Developmental Psychology, 21, 842-847.

Gunn, P., \& Crombie, M. (1996). Language and speech. In B. Stratford \& P. Gunn (eds) New Approaches to Down Syndrome (pp. 249-267). London: Cassell.

Gunn, P., \& Cuskelly, M. (1991). Down syndrome temperament: The stereotype at middle childhood and adolescence. International Journal of Disability, Development, and Education, 38, 59-70.

Harris, S., Kasari, C., \& Sigman, M.D. (1996). Joint attention and language gains in children with Down syndrome. American Journal on Mental Retardation, 100, 608-619.

Jay, A.S., Grote, I., \& Baer, D.M. (1999). Teaching participants with developmental disabilities to comply with selfinstructions. American Journal on Mental Retardation, 104, 509-522.

Kendall, P.C. (1990). Challenges for cognitive strategy training: The case of mental retardation. American Journal on Mental Retardation, 94, 365-367.

Kendall, P.C. \& Wilcox, L.E. (1979) Self-control in children: Development of a rating scale. Journal of Consulting and Clinical Psychology, 47, 1020-1029.

Kochanska, G., Murray, K., Jacques, T.Y., Koenig, A.L., \& Vandegeest, K.A. (1996). Inhibitory control in young children and its role in emerging internalization. Child Development, 67, 490-507.

Kopp, C (1982). Antecedents of self-regulation: A developmental perspective. Developmental Psychology, 18, 199-214.

Kopp, C. (1990). The growth of self-monitoring among young children with Down syndrome. In D. Cicchetti, \& M. Beeghly (eds), Children with Down Syndrome: A Developmental Perspective (pp. 231-251). Cambridge: Cambridge University Press.

Kopp, C. (1991). Young children's progression to self-regulation. In M. Bullock (ed), The Development of Intentional Action: Cognitive, Motivational, and Interactive processes: Vol 22. Contribution to Human Development (pp. 38-54). Basel: Kager.

Logue, A.W., King, G.R., Chavarro, A., \& Volpe, J.S. (1990). Matching and maximising in a self-control paradigm using human subjects. Learning and Motivation, 21, 340-368.

Luria, A.R. (1961). The Role of Speech in the Regulation of Normal and Abnormal Behavior. London: Pergamon Press.

Mischel, H.N., \& Mischel, W. (1983). The development of children's knowledge of self-control strategies. Child Development, 54, 603-619.

Mischel, W. (1974). Processes in delay of gratification. In L. Berkowitz (Ed), Advances in Experimental Social Psychology, (vol 7, pp. 249-292). New York: Academic Press.

Mischel, W., Shoda, Y., \& Rodriguez, M. (1989). Delay of gratification in children. In G. Loewenstein, \& J. Elster, (Eds), Choice Over Time (pp. 147-164). New York: Russell Sage Foundation.

Pulman, L. (1999). Lexical development in children and young adults with Down syndrome: Incorporating an equivalence study of the PPVT-R and the PPVT-III.
Unpublished master's thesis, University of Queensland, Brisbane, Australia.

Reed, M.A., Pien, D.L., \& Rothbart, M.K. (1984). Inhibitory self-control in preschool children. Merrill-Palmer Quarterly, 30, 131-147.

Rodriguez, M. L., Mischel, W., \& Shoda, Y. (1989). Cognitive person variables in the delay of gratification of older children at risk. Journal of Personality and Social Psychology, 57, 358-367.

Rothbart, M.K., \& Jones, L.B. (1998). Temperament, selfregulation, and education. School Psychology Review, 27, 479-491.

Rowe, D.C. \& Plomin, R. (1977). Temperament in early childhood. Journal of Personality Assessment, 41, 150-156.

Shoda, Y., Mischel, W., \& Peake, P. (1990). Predicting adolescent cognitive and self-regulatory competencies from preschool delay of gratification: Identifying diagnostic conditions. Developmental Psychology, 26, 978-986.

Silverman, I.W., \& Ragusa, D.M. (1990). Child and maternal correlates of impulse control in 24-month-old children. Genetic, Social, and General Psychology Monographs, 116, 437-473.

Vaughn, B.E., Kopp, C.B., \& Krakow, J.B. (1984). The emergence and consolidation of self-control from eighteen to thirty months of age: Normative trends and individual differences. Child Development, 55, 990-1004.

Vygotsky, L.S. (1962). Thought and Language. Cambridge: MIT Press and Wiley.

Whitman, T.L. (1990). Self-regulation and mental retardation. American Journal on Mental Retardation, 94, 297-333.

Whitman T.L., O'Callaghan, M., \& Sommer, K. (1997). Emotion and mental retardation. In W.E. McLean, Jr. (ed), Ellis' Handbook of Mental Deficiency, Psychological Theory and Research, $3^{\text {rd }}$ edition (pp. 77-98). Mahwah, NJ: Erlbaum.

Williams, K.T. (1997). Expressive Vocabulary Test. Circle Pines, MN: American Guidance Service.

Zhang, A., \& Cuskelly, M. (2000). Delay of gratification in young children with Down syndrome. Paper presented at 7th World Congress on Down syndrome, Sydney, 23-26 March. 